\title{
Fuzzy Tuning PID Control of Strip Rolling Mill Hydraulic APC System
}

\author{
Liping Fan ${ }^{1, *}$, Xiaolin $\mathrm{Shi}^{2}$, Ruoran Wang ${ }^{3}$ \\ ${ }^{I}$ College of Environment and Safety Engineering, Shenyang University of \\ Chemical Technology, Shenyang 110142, China. \\ ${ }^{2}$ College of Information Engineering, Shenyang University of Chemical \\ Technology, Shenyang 110142, China, \\ ${ }^{3}$ Branch Company of Rolling Equipment, North Heavy Industry Group \\ Co., Ltd, Shenyang, 110141, China. \\ "flpsd@163.com
}

\begin{abstract}
Hydraulic Automatic Position Control (APC) is a very important part of rolling mill for magnesium plate rolling. The control effect of automatic position control system influences the quality of the rolled product directly. APC system is an essentially nonlinear, time delay, time-varying, large inertia, multivariable and coupling complex system, which increase the designing difficulty of control system. Based on the mathematical model of the automatic position control system, a simulation platform of rolling mill is set up, and a fuzzy tuning PID controller is designed to realize position control for the hydraulic system. The control effect of the proposed fuzzy tuning PID controller is compared with that of a general PID controller whose parameters was adjusted by Ziegler-Nichols method. Simulation results show that the fuzzy tuning PID controller can give satisfactory control effect.
\end{abstract}

Keywords:Strip Rolling Mill; Hydraulic APC System; Sliding Mode Control. 


\section{Introduction}

Control technology for strip mill hydraulic automatic position control has experienced by the coarse-to-fine process of development. The traditional thickness control systems generally use the classic PID controller to achieve. Conventional PID control has the advantages of simplicity, convenience, suitability and robustness, so it is widely adopted for industrial control. APC system is an essentially nonlinear, time delay, time-varying, large inertia, multivariable and coupling complex system [1]. As the complexity of the control object, the precise mathematical model of the control system cannot be established, and there are disturbances caused by internal parameters and external load and some other uncertainties, these factors increase the designing difficulty of control system [2-4]. Because of the existing of some difficulties such as parameters tuning, traditional PID control have been increasingly unable to meet the control requirements [5-6].

As an important branch of theintelligent control, fuzzy control has been widely used in power, chemical, metallurgyand some other industrial control. However, fuzzy control lacks a formal synthesistechnique and all fuzzy rules must be supplied by human experts. It also has theshortcomings of poor stability and low precision [7-8]. Fuzzy PID control which combinesthe traditional PID control and the fuzzy control algorithm is a solution to improve theadaptive ability of a PID controller and meanwhile overcome the shortage of a fuzzycontroller on stability precision [9]. By means of fuzzy auto-tuning online of PIDparameters, it can modify the PID parameters in real time, and make the system run at theoptimal status all the time.A fuzzy tuning PID controller is designed for the hydraulic APC system in this paper.

\section{Modelling of the APC system}

The main component of hydraulic APC system contains electro-hydraulic servo valve, hydraulic cylinder, rolling mill and displacement sensor.The control 
principle is shown in Fig. 1. A simplified block diagram of hydraulic APC system is shown in Fig.2.

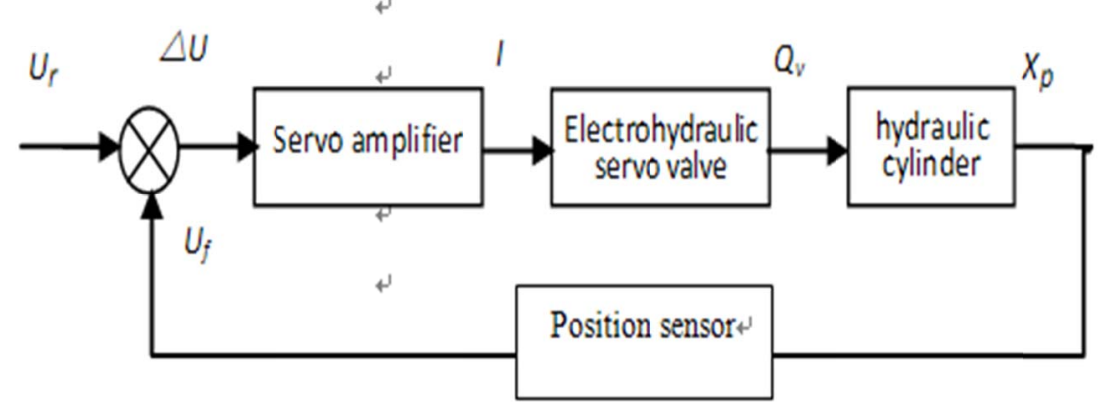

Fig. 1 Schematics of a hydraulic APC system

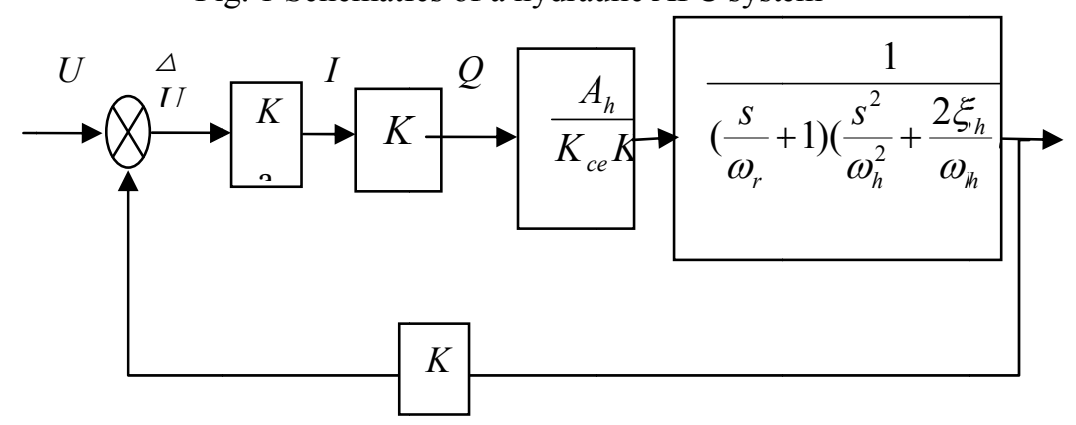

Fig. 2Model diagram of a hydraulic APC system

\section{Controller design}

The fuzzy tuning PID controller block diagram is shown in Fig. 3.Adual inputs fuzzy controller is added to the double-loop speed regulating system to adjust the three parameters of the speed controller of the rolling mill main drive system. The speed controller is still the upper mentioned designed PID controller. The inputs of the fuzzy controller are the speed error e and the change of error ec, The three outputs $\mathrm{Kp}, \mathrm{Ki}, \mathrm{Kd}$ of the fuzzy controller are used as the parameter of the PID controller.The fuzzy set for inputs and outputs is chosen as the consistent fuzzy set $\{\mathrm{NB}, \mathrm{NM}, \mathrm{NS}, \mathrm{ZE}, \mathrm{PS}, \mathrm{PM}, \mathrm{PB}\}$. The fuzzy control rule bases for Kp, Ki, Kd are shown in Table.1 to Table.3, respectively. 


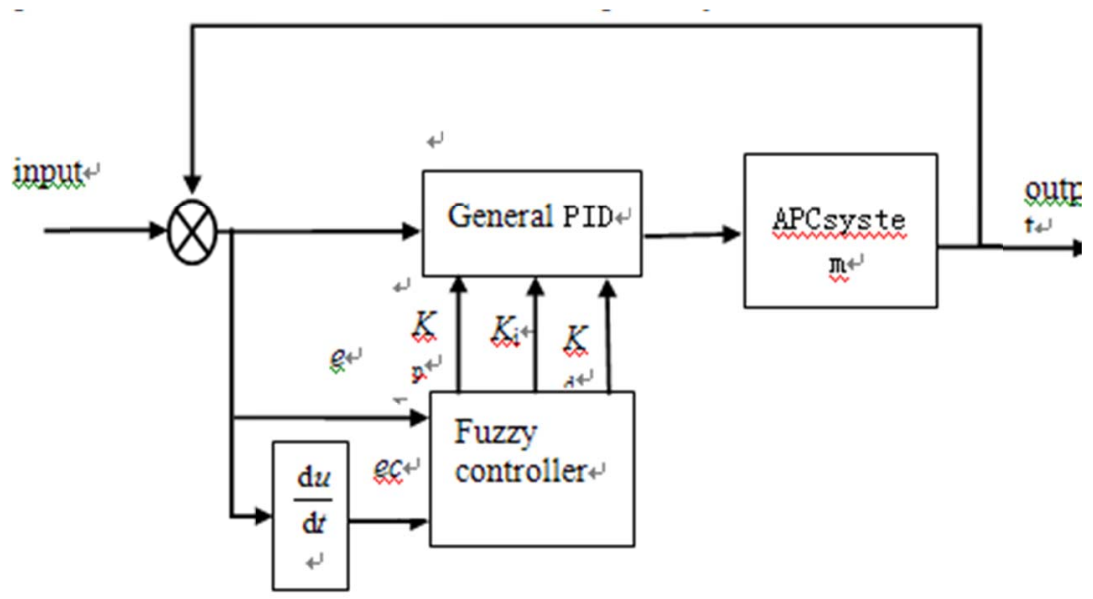

Fig. 3Structure diagram of the fuzzy tuning PID control system

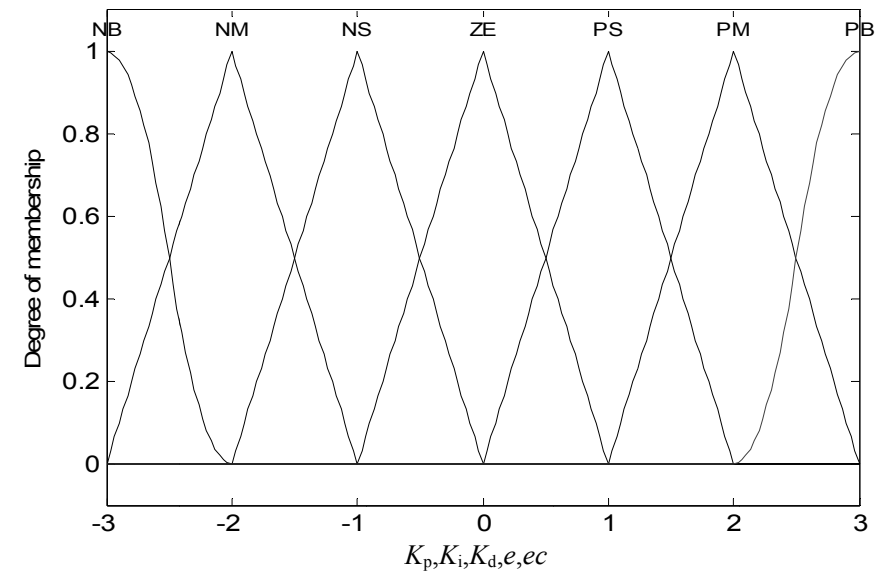

Fig.4 The membership function of the inputs and output of the fuzzy controller

Table. 1 Fuzzy rules for $K_{\mathrm{p}}$

\begin{tabular}{ccccccccc}
\hline \multirow{2}{*}{$K_{i}$} & \multicolumn{7}{c}{$\Delta e(k)$} \\
\cline { 3 - 8 } & & NB & NM & NS & ZO & PS & PM & PB \\
\hline \multirow{4}{*}{$e(k)$} & NB & PB & PB & PM & PM & PS & ZO & ZO \\
& NM & PM & PM & PS & PS & PS & ZO & NS \\
& NS & PM & PM & PS & ZO & ZO & NS & NS \\
& ZO & PM & PS & PS & ZO & ZO & NS & NM \\
& PS & PM & PS & NS & NS & NS & NB & NM \\
& PM & PS & PS & NS & NS & NS & NM & NB
\end{tabular}




\begin{tabular}{|c|c|c|c|c|c|c|c|c|}
\hline & $\mathrm{PB}$ & PS & NS & NS & NM & NM & NM & NB \\
\hline \multicolumn{9}{|c|}{ Table.2 Fuzzy rules for $K_{\mathrm{i}}$} \\
\hline \multirow{2}{*}{\multicolumn{2}{|c|}{$K_{i}$}} & \multicolumn{7}{|c|}{$\Delta e(k)$} \\
\hline & & NB & NM & $\mathrm{NS}$ & $\mathrm{ZO}$ & PS & PM & $\mathrm{PB}$ \\
\hline \multirow{7}{*}{$e(k)$} & NB & NB & NB & NM & NM & NS & $\mathrm{ZO}$ & $\mathrm{ZO}$ \\
\hline & NM & NB & NB & NM & NS & NS & $\mathrm{ZO}$ & $\mathrm{ZO}$ \\
\hline & NS & NB & NM & NS & NS & $\mathrm{ZO}$ & PS & PS \\
\hline & $\mathrm{ZO}$ & NM & NM & NS & $\mathrm{ZO}$ & PS & $\mathrm{PM}$ & $\mathrm{PM}$ \\
\hline & PS & NM & NS & $\mathrm{ZO}$ & PS & PS & PM & PB \\
\hline & PM & $\mathrm{ZO}$ & $\mathrm{ZO}$ & PS & PS & PM & $\mathrm{PB}$ & PB \\
\hline & $\mathrm{PB}$ & $\mathrm{ZO}$ & $\mathrm{ZO}$ & PS & $\mathrm{PM}$ & $\mathrm{PM}$ & $\mathrm{PB}$ & PB \\
\hline \multicolumn{9}{|c|}{ Table.3 Fuzzy rules for $K_{\mathrm{d}}$} \\
\hline \multirow{2}{*}{\multicolumn{2}{|c|}{$K_{d}$}} & \multicolumn{7}{|c|}{$\Delta e(k)$} \\
\hline & & NB & NM & NS & $\mathrm{ZO}$ & PS & PM & PB \\
\hline \multirow{7}{*}{$e(k)$} & NB & PS & NS & NB & NB & NB & NM & PS \\
\hline & NM & PS & NS & NB & NM & NM & NS & $\mathrm{ZO}$ \\
\hline & NS & $\mathrm{ZO}$ & NS & NM & $\mathrm{NM}$ & NS & NS & $\mathrm{ZO}$ \\
\hline & $\mathrm{ZO}$ & $\mathrm{ZO}$ & NS & NS & $\mathrm{ZO}$ & NS & NS & $\mathrm{ZO}$ \\
\hline & PS & $\mathrm{ZO}$ & $\mathrm{ZO}$ & $\mathrm{ZO}$ & NS & $\mathrm{ZO}$ & $\mathrm{ZO}$ & $\mathrm{ZO}$ \\
\hline & PM & PB & PS & PS & PS & PS & PS & PB \\
\hline & PB & PB & $\mathrm{PM}$ & PM & $\mathrm{PM}$ & PS & PS & PB \\
\hline
\end{tabular}

\section{Simulation and Results Analysis}

In order to test the effectiveness of the proposed control scheme, simulation operations are carried out in MATLAB/SIMULINK simulation platform. The simulation results are shown in Fig. 5.It can be seen from the results that the proposed fuzzy PID have better control effect than general PID. 


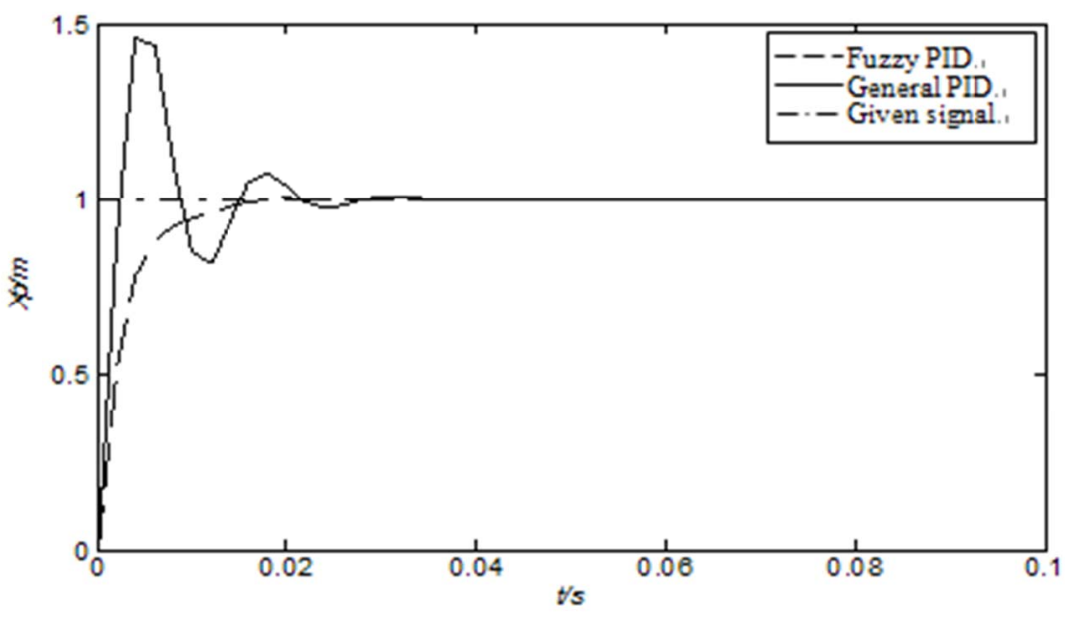

Fig.5 Simulation results

\section{Acknowledgements}

This work was supported by the National Key Technology Research and Development Program ofChina under Grant 2012BAF09B01.

\section{References}

[1] B. H. Yang, W.D. Yang, L. G. Chen, L. Qu, Dynamic Optimization of Feedforward Automatic Gauge Control Based on Extended Kalman Filter, Journal of Iron and Steel Research International, vol. 15 (2008), p. 39- 42.

[2] Y. Fang, Z. X. Jiao, W. B. Wang, P. Z. Shao, Adaptive Backstepping Sliding Mode Control for Rolling Mill Hydraulic Servo Position System, Electric Machines and Control (in China), vol. 15 (2011) , p. 95-100.

[3] Z.Wu, Q.Xia, Y.Peng, J.Sun. Backstepping Dynamic Surface Control for High-order Nonlinear Hydraulic Roll Gap System. Chinese Journal of Scientific Instrument(in China), vol. 33 (2012), p. 949-954.

[4] J. X. Li, Y. M. Fang, S. L. Shi, Robust Output-Feedback Control for Hydraulic Servo-Position System of Cold-Strip Rolling Mill, Control Theory \& Applications, vol. 29 (2012), p. 331-336. 
[5] Z. Li,Model Reference Adaptive Controller Design Based on Fuzzy Inference System, Journal of Information \& Computational Science,vol. 8 (2011), p. 1683-1693.

[6] T. Gong and L. Qi,Novel ARM-based Gauge Control System with Fuzzy PI Controller, International Journal of Multimedia and Ubiquitous Engineering, vol. 7 (2012), p. 527-532.

[7] M. Ali, S. Khan, M. Waleed and Islamuddin. Application of an Intelligent self-tuning fuzzy PID controller on DC-DC buck converter, International Journal of Advanced Science and Technology, vol.48 (2012), p.139-148.

[8] S. Gharghory and H. Kamal. Modified PSO for optimal tuning of fuzzy PID controller, International Journal of Computer Science Issues, vol. 10(2013), p. $462-471$.

[9] C. H. Ao. Parameter auto-tuning method based on self-learning algorithm, Journal of Computers vol. 7 (2012), p. 2168-2175. 